\title{
Associação entre Adesão à Medicação para o HIV e Aspectos Sociodemográficos, Econômicos, Comportamentais e Clínicos
}

\author{
Samuel Spiegelberg Zuge, ${ }^{1}$ Crhis Netto de Brum, ${ }^{2}$ João Vitor Valente, ${ }^{3}$ \\ Danieli Covalski, ${ }^{4}$ Daniela Graczyk, ${ }^{4}$ Carina Rossoni ${ }^{5}$
}

\begin{abstract}
RESUMO
Objetiva-se analisar a associação entre os aspectos sociodemográficos, econômicos, comportamentais e clínicos e a adesão à terapia antirretroviral para o Vírus da Imunodeficiência Humana (HIV). Trata-se de um estudo transversal, realizado em três municípios do Oeste de Santa Catarina, nos serviços de assistência especializada (SAE) para o HIV, no qual participaram 114 pessoas em terapia antirretroviral. A coleta de dados foi realizada no período de janeiro a março de 2017, sendo utilizado um instrumento contendo aspectos sociodemográficos, econômicos, comportamentais e clínicos e o Cuestionário para la Evaluación de la Adhesión al Tratamiento Antiretroviral. Realizou-se análises bivariadas e de regressão de Poisson. A adesão à terapia antirretroviral para o HIV esteve associada às pessoas com idade superior a 40 anos, que estão de um a três anos em tratamento, que manifestaram facilidade em realizar o acompanhamento no serviço de saúde, que já apresentaram alguma doença oportunista e as que não apresentavam alguma condição psiquiátrica. Conclui-se que a idade, o tempo de tratamento, o acompanhamento no serviço de saúde, apresentar alguma doença oportunista e não ter nenhuma condição psiquiátrica, estão associados significativamente com a adesão à terapia antirretroviral.
\end{abstract}

Palavras-chave: HIV; síndrome da imunodeficiência adquirida; terapia antirretroviral de alta atividade; adesão à medicação; determinantes sociais da saúde.

\section{ASSOCIATION BETWEEN ADHERENCE TO HIV MEDICATION AND SOCIODEMOGRAPHIC, ECONOMIC, BEHAVIORAL, AND CLINICAL ASPECTS}

\section{ABSTRACT}

The objective is to analyze the association between sociodemographic, economic, behavioral and clinical aspects and adherence to antiretroviral therapy for the Human Immunodeficiency Virus (HIV). This is a cross-sectional study, carried out in three municipalities in the West of Santa Catarina, in specialized HIV services (SAE) for HIV, in which 114 people participated in antiretroviral therapy. Data collection was carried out from January to March 2017, using an instrument containing sociodemographic, economic, behavioral, and clinical aspects and the Cuestionário para la Evaluación de la Adhesión al Tratamiento Antiretroviral. Bivariate and Poisson regression analyzes were performed. Adherence to antiretroviral therapy for HIV was associated with people over the age of 40, who are in one to three years of treatment, who showed ease in carrying out follow-up at the health service, who already had some opportunistic disease and people who did not have any psychiatric condition. It was concluded that age, length of treatment, follow-up at the health service, having any opportunistic illness and not having any psychiatric condition are significantly associated with adherence to antiretroviral therapy.

Keywords: HIV; Acquired immunodeficiency syndrome; Antiretroviral therapy highly active; medication adherence. social determinants of health.

RECEBIDO EM: $11 / 1 / 2021$

MODIFICAÇÕES SOLICITADAS EM: 2/2/2021

ACEITO EM: 26/2/2021

\footnotetext{
${ }^{1}$ Autor correspondente. Universidade Comunitária da Região de Chapecó. Servidão Anjo da Guarda, 295D - Efapi. Chapecó/SC, Brasil. CEP 89809-900. http://lattes.cnpq.br/6932635466265896. https://orcid.org/0000-0002-0420-9122 samuelzuge@gmail.com

2 Universidade Federal da Fronteira Sul - UFFS, Campus Chapecó. Chapecó/SC, Brasil.

${ }^{3}$ Universidade Comunitária da Região de Chapecó - Unochapecó. Chapecó/SC, Brasil.

${ }^{4}$ Universidade do Oeste de Santa Catarina - Unoesc. Chapecó/SC, Brasil.

${ }^{5}$ Instituto de Saúde Ambiental da Faculdade de Medicina - Universidade de Lisboa. Lisboa/Portugal
} 


\section{INTRODUÇÃO}

Mundialmente, cerca de 38 milhões de pessoas vivem com a infecção pelo Vírus da Imunodeficiência Humana (HIV)1. Já, no Brasil, o número de notificações até 2020 representa 1.011.617 pessoas. Além disso, o número de óbitos, em 2019, totalizou 10.565 óbitos, com uma taxa de mortalidade de 4,1 pessoas a cada cem mil habitantes, o qual reduziu cerca de $28,1 \%$ nos últimos anos ${ }^{2}$. Foi a partir da introdução da terapia antirretroviral que houve uma transformação no tratamento e na vida das pessoas, uma vez que a condição imposta pela doença, considerada potencialmente fatal, passou a ser concebida como uma doença crônica gerenciávele ${ }^{3-4}$.

Assim, para garantir a eficácia da terapia antirretroviral, que visa a proporcionar a obtenção da supressão viral, redução da morbidade e mortalidade causadas pelo HIV, melhora na qualidade de vida e de saúde, além de agir como meio de prevenção da transmissão do HIV, torna-se necessário manter a adesão à terapia ${ }^{5-6}$. $O$ termo adesão ainda não apresenta um consenso sobre seu conceito, pois existem inúmeros aspectos que são pontuados sobre sua definição, que vão desde a ingestão do medicamento até mesmo a condições comportamentais, e que prejudica sua mensuração e seu processo de avaliação ${ }^{3}$, no entanto, neste estudo, a adesão será definida a partir do seguimento da prescrição médica, e está implicada a condições comportamentais do próprio sujeito, que podem ter reflexos sobre a ingestão do medicamento ${ }^{7}$.

A adesão mundialmente é considerada uma problemática, pois resultados de estudos de metanálise têm apontado que a média mundial de adesão à terapia antirretroviral varia de $62 \%^{8}$ a $63,4 \%$. Na região da América Latina, porém, os dados são mais promissores, apresentando melhores níveis de adesão, posto que a prevalência de adesão à terapia antirretroviral foi de $70 \%{ }^{10}$. Já um estudo que avaliou a prevalência da adesão à terapia antirretroviral no Brasil, identificou uma variação de adesão de $18 \%$ a $74,3 \%{ }^{11}$.

O sucesso da adesão adquire um caráter dinâmico influenciado por inúmeros fatores ${ }^{12}$, dentre eles as características sociodemográficas e econômicas, os aspectos clínicos e comportamentais dos indivíduos ${ }^{13-15}$. Neste contexto, percebe-se que nos últimos anos realizaram-se esforços mundiais a fim de melhorar os níveis de adesão, e dentre eles a identificação dos determinantes sociais da saúde que podem influenciar a realização da terapia antirretroviral, favorecendo o desenvolvimento de intervenções que proporcionem a melhora da qualidade de vida e saúde desta população, além de contribuir para a supressão viral, que diminuirá as chances de transmissão do vírus.

Assim, este estudo teve como hipótese que os aspectos sociodemográficos, econômicos, comportamentais e clínicos influenciam na adesão à terapia antirretroviral para o HIV. O objetivo é analisar a associação entre os aspectos sociodemográficos, econômicos, comportamentais e clínicos e a adesão à terapia antirretroviral para o HIV.

Editora Unijuí - Revista Contexto \& Saúde - ISSN 2176-7114 - v. 21, n. 44, out./dez. 2021 


\section{MÉTODO}

Estudo quantitativo, de cunho transversal, realizado em três municípios do Oeste de Santa Catarina, nos serviços de assistência especializada (SAE) para o HIV. Participaram do estudo pessoas com a infecção pelo HIV e em terapia antirretroviral, há pelo menos três meses no serviço, no seguimento populacional de adultos com idade maior e igual a 20 anos de ambos os sexos. Foram excluídas do estudo as mulheres que estivessem em período gravídico puerperal, em decorrência de o tratamento atender principalmente as expectativas profiláticas para o recém-nascido.

A coleta de dados foi realizada no período de janeiro a março de 2017, sendo os participantes selecionados por conveniência, a partir da demanda do $\mathrm{SAE}$, entre os períodos das consultas médicas, de enfermagem, da psicologia e durante a dispensação dos medicamentos pela farmácia. A coleta de dados foi realizada pelo pesquisador principal e por integrantes do grupo de pesquisa por meio de um questionário de avaliação dos aspectos sociodemográficos, econômicos, comportamentais e clínicos e o Cuestionário para la Evaluación de la Adhesión al Tratamiento Antiretroviral (Ceat-VIH), desenvolvido ${ }^{16}$ e validado para o Brasil ${ }^{17}$ após a equipe ser capacitada para sua utilização.

O questionário de avaliação dos aspectos sociodemográficos, econômicos, comportamentais e clínicos foi criado pelos próprios autores, contendo: 1) aspectos sociodemográficos e econômicos que continham as variáveis: sexo, idade, raça, nível de escolaridade, número de filhos, situação conjugal, situação empregatícia e renda familiar; 2) aspectos comportamentais: ingestão de bebida alcoólica; propensão para o alcoolismo; acompanhamento no serviço de saúde; e 3) aspectos clínicos: tempo de tratamento, quantidade de comprimidos que ingere diariamente, se apresenta alguma condição psiquiátrica e se tem alguma doença oportunista.

O Ceat-VIH busca avaliar a adesão à terapia antirretroviral para o HIV em uma perspectiva multidimensional, considerando que a adesão geral envolve aspectos relacionados ao comportamento na ingestão do medicamento, além de levar em conta as dificuldades e as barreiras percebidas pelos indivíduos no cumprimento da terapia. O questionário contém 20 questões e possibilita uma avaliação global da adesão, sendo obtida pela soma de todos os itens, variando de 17 pontos (mínimo) a 89 pontos (máximo) ${ }^{16,18}$.

Assim, quanto maior for a pontuação da avaliação da adesão maior é o grau de adesão do indivíduo. Além disso, a avaliação da adesão (desfecho) neste estudo foi estratificada de forma dicotômica em não adesão (escore bruto $\leq 74$ ), que representa uma adesão inadequada, baixa ou insuficiente, e adesão (escore bruto $\geq 75$ ) que representa uma adesão boa, adequada ou estrita ${ }^{15}$. Além disso, foi realizada a avaliação da consistência interna do Ceat-VIH, obtida a partir da amostra deste estudo, por meio do coeficiente de Alpha de Cronbach $(\alpha=0,73)$.

Os dados foram tabulados no software Epi-info ${ }^{\circledR}$, versão 7.0, a partir de dupla digitação, de forma independente, e, após avaliação de erros e inconsistência, foram analisados no software PASW Statistics ${ }^{\circledR}$ (Predisctive Analytics Software, da SPSS Inc., Chicago-USA), versão 20.0 for Windows. Foram realizadas 
análises de frequência e descritiva e análises de inferência entre a variável de desfecho e demais variáveis. Para o desenvolvimento das análises bivariadas foram realizados os testes de quiquadrado de Pearson ou exato de Fisher, relacionando as variáveis que dizem respeito aos aspectos sociodemográficos, econômicos, comportamentais e clínicos (variáveis independentes) e à adesão (variável desfecho).

Além disso, foram realizadas análises de regressão de Poisson com variância robusta. O critério para a entrada das variáveis relacionadas aos aspectos sociodemográficos, econômicos, comportamentais e clínicos no modelo de regressão foi apresentar o valor $p<0,20$ na análise bivariada. Após, o critério para a permanência das variáveis no modelo foi de que apresentasse um valor $p<0,10$ no modelo final. Destaca-se que o nível de significância adotado em todas as análises foi de $5 \%$.

O estudo recebeu aprovação do Comitê de Ética em Pesquisa da Universidade do Oeste de Santa Catarina, sob parecer número 1.647.700/2016.

\section{RESULTADOS}

Participaram da pesquisa 114 pessoas em terapia antirretroviral para o HIV, posto que $61,4 \%$ apresentaram adesão boa, adequada ou estrita à terapia. A média da adesão foi 75,95 \pm 7,48, variando os escores de 49 a 80 pontos.

Sobre a população do estudo ressalta-se que $57 \%$ eram do sexo masculino, com idade média de 41,6 anos de idade $\pm 12,01$ (21 a 62 anos), 67,5\% eram da raça/etnia branca, 49,1\% não haviam estudado ou somente até o Ensino Fundamental, 43,9\% apresentaram de dois a três filhos, 59,1\% viviam com esposo(a) ou companheiro(a), 57,9\% apresentavam vínculo empregatício e 50,9\% tinham renda mensal de um a dois salários mínimos. Em relação aos aspectos comportamentais das pessoas, 36,8\% ingeriam bebida alcoólica e, destes, 90,5\% apresentaram propensão para o alcoolismo. Além disso, 66,7\% relataram que possuíam facilidade para realizar o acompanhamento no serviço de saúde (Tabela 1 ).

Tabela 1 - Aspectos sociodemográficos, econômicos e comportamentais de pessoas com a infecção pelo HIV e a relação com a adesão à terapia antirretroviral. $n=114$. Chapecó (SC), Brasil, 2017

\begin{tabular}{|c|c|c|c|c|c|}
\hline \multirow{2}{*}{ Variáveis } & \multicolumn{2}{|c|}{ Não Adesão } & \multicolumn{2}{|c|}{ Adesão } & \multirow{2}{*}{$\mathrm{p}$-value } \\
\hline & $\mathbf{N}$ & $\%$ & $\mathbf{N}$ & $\%$ & \\
\hline \multicolumn{6}{|l|}{ Sexo } \\
\hline Masculino & 21 & 32,3 & 44 & 67,7 & 0,112 \\
\hline Feminino & 23 & 46,9 & 26 & 53,1 & \\
\hline \multicolumn{6}{|l|}{ Idade } \\
\hline 21 a 39 anos & 26 & 50,0 & 26 & 50,0 & 0,022 \\
\hline Maior e igual a 40 anos & 18 & 29,0 & 44 & 71,0 & \\
\hline \multicolumn{6}{|l|}{ Raça/Etnia } \\
\hline Branca & 23 & 29,9 & 54 & 70,1 & 0,006 \\
\hline Outra raça* & 21 & 56,8 & 16 & 43,2 & \\
\hline
\end{tabular}




\begin{tabular}{|c|c|c|c|c|c|}
\hline \multirow{2}{*}{ Variáveis } & \multicolumn{2}{|c|}{ Não Adesão } & \multicolumn{2}{|c|}{ Adesão } & \multirow{2}{*}{$p$-value } \\
\hline & $\mathbf{N}$ & $\%$ & $\mathbf{N}$ & $\%$ & \\
\hline \multicolumn{6}{|l|}{ Nível de Escolaridade } \\
\hline Não estudou ou estudou até Ensino & 20 & 35,7 & 36 & 64,3 & \multirow{4}{*}{0,050} \\
\hline Fundamental & & & & & \\
\hline Até o Ensino Médio & 18 & 54,5 & 15 & 45,5 & \\
\hline Até o Ensino Superior & 6 & 24,0 & 19 & 76,0 & \\
\hline \multicolumn{6}{|l|}{ Número de filhos } \\
\hline Nenhum filho & 11 & 36,7 & 19 & 63,3 & \multirow{3}{*}{0,928} \\
\hline Um filho a dois filhos & 19 & 38,0 & 31 & 62,0 & \\
\hline Mais de dois filhos & 14 & 41,2 & 20 & 58,8 & \\
\hline \multicolumn{6}{|l|}{ Situação Conjugal } \\
\hline Vive com esposo(a)/ companheiro(a) & 26 & 38,2 & 42 & 61,8 & \multirow[t]{2}{*}{0,923} \\
\hline Vive sozinho(a) & 18 & 39,1 & 28 & 60,9 & \\
\hline \multicolumn{6}{|l|}{ Situação empregatícia } \\
\hline Empregado & 22 & 33,3 & 44 & 66,7 & \multirow[t]{2}{*}{0,176} \\
\hline Não Empregado & 22 & 45,8 & 26 & 54,2 & \\
\hline \multicolumn{6}{|l|}{ Renda familiar** } \\
\hline Até dois salários mínimos & 28 & 48,3 & 30 & 51,7 & \multirow[t]{2}{*}{0,031} \\
\hline Mais de dois salários mínimos & 16 & 28,6 & 40 & 71,4 & \\
\hline \multicolumn{6}{|l|}{ Ingestão de bebidas alcoólicas } \\
\hline Sim & 15 & 35,7 & 27 & 64,3 & \multirow[t]{2}{*}{0,629} \\
\hline Não & 29 & 40,3 & 43 & 59,7 & \\
\hline \multicolumn{6}{|l|}{ Propensão para o alcoolismo ( $n=42)$} \\
\hline $\operatorname{Sim}$ & 4 & 100,0 & 0 & 0 & \multirow[t]{2}{*}{$0,012 * * *$} \\
\hline Não & 11 & 28,9 & 27 & 71,1 & \\
\hline \multicolumn{6}{|l|}{ Acompanhamento no serviço de saúde } \\
\hline Apresenta facilidades & 22 & 28,9 & 54 & 71,0 & \multirow[t]{2}{*}{0,003} \\
\hline Apresenta dificuldades & 22 & 57,9 & 16 & 42,1 & \\
\hline
\end{tabular}

Ao relacionar os aspectos sociodemográficos e econômicos e a adesão, foi possível identificar relação estatística significativa com a idade $(p=0,022)$, a raça $(p=0,006)$, o grau de escolaridade $(p=0,050)$ e a renda familiar $(p=0,031)$. Já em relação aos aspectos comportamentais foi possível identificar relação estatística significativa com a propensão para o alcoolismo $(p=0,012)$ e o acompanhamento no serviço de saúde $(p=0,003)$ (Tabela 1 ).

Diante dos aspectos clínicos, salienta-se que 68,4\% apresentavam diagnóstico a mais de três anos, 28,9\% ingeriam mais de três antirretrovirais diariamente, $12,3 \%$ tinham alguma condição psiquiátrica e 38,9\% já haviam apresentado alguma doença oportunista. Ao relacioná-los com a adesão foi possível identificar relação estatística significativa com as variáveis: apresenta alguma condição psiquiátrica $(p=0,036)$ e se já haviam apresentado alguma doença oportunista $(p=0,018)$ (Tabela 2). 
Tabela 2 - Aspectos clínicos de pessoas com a infecção pelo HIV e a relação com a adesão à terapia antirretroviral. $n=114$. Chapecó (SC), Brasil, 2017

\begin{tabular}{|c|c|c|c|c|c|}
\hline \multirow{2}{*}{ Variáveis } & \multicolumn{2}{|c|}{ Não Adesão } & \multicolumn{2}{|c|}{ Adesão } & \multirow{2}{*}{$\mathrm{p}$-value } \\
\hline & $\mathbf{N}$ & $\%$ & $\mathbf{N}$ & $\%$ & \\
\hline \multicolumn{6}{|l|}{ Tempo de tratamento } \\
\hline De 1 a 3 anos & 10 & 27,8 & 26 & 72,2 & \multirow[t]{2}{*}{0,107} \\
\hline Mais de 3 anos & 34 & 43,6 & 44 & 56,4 & \\
\hline \multicolumn{6}{|c|}{ Quantos comprimidos ingere diariamente } \\
\hline De 1 a 3 comprimidos & 30 & 37,0 & 51 & 63,0 & \multirow[t]{2}{*}{0,592} \\
\hline Mais de 3 comprimidos & 14 & 42,4 & 19 & 57,6 & \\
\hline \multicolumn{6}{|c|}{ Apresenta alguma condição psiquiátrica } \\
\hline Sim & 9 & 64,3 & 5 & 35,7 & \multirow[t]{2}{*}{0,036} \\
\hline Não & 35 & 35,0 & 65 & 65,0 & \\
\hline \multicolumn{6}{|c|}{ Apresentou alguma doença oportunista } \\
\hline Sim & 11 & 25,0 & 33 & 75,0 & \multirow[t]{2}{*}{0,018} \\
\hline Não & 33 & 47,1 & 37 & 52,9 & \\
\hline
\end{tabular}

Após o ajuste do modelo de regressão de Poisson os preditores idade, tempo de tratamento, acompanhamento no serviço de saúde, presença de doenças oportunistas e alguma condição psiquiatra se associaram significativamente com a adesão à terapia antirretroviral para o HIV (Tabela 3).

Tabela 3 - Associação dos aspectos sociodemográficos, econômicos, comportamentais e clínicos de pessoas com a infecção pelo HIV e a adesão à terapia antirretroviral. $n=114$. Chapecó (SC), Brasil, 2016-2017

\begin{tabular}{|c|c|c|c|c|c|c|}
\hline \multirow{2}{*}{ Variáveis } & \multicolumn{6}{|c|}{ Adesão } \\
\hline & $\mathbf{R P b}$ & IC 95\% & $p$-value & RPaj & IC 95\% & $p$-value \\
\hline \multicolumn{7}{|l|}{ Sexo } \\
\hline Feminino & 1,14 & $0,8-1,6$ & 0,405 & & & \\
\hline Masculino & 1 & & & & & \\
\hline \multicolumn{7}{|l|}{ Raça } \\
\hline Branca & 1,49 & $1,0-2,2$ & 0,033 & 1,4 & $1,0-2,0$ & 0,055 \\
\hline Outras raças & 1 & & & 1 & & \\
\hline \multicolumn{7}{|l|}{ Idade } \\
\hline 40 anos ou mais & 1,82 & $1,4-2,5$ & 0,000 & 1,9 & $1,4-2,5$ & 0,000 \\
\hline 21 aos 39 anos & 1 & & & 1 & & \\
\hline \multicolumn{7}{|l|}{ Escolaridade } \\
\hline Estudou até o Ensino Superior & 0,78 & $0,6-1,0$ & 0,078 & & & \\
\hline Estudou até o Ensino Médio & 0,71 & $0,5-1,1$ & 0,103 & & & \\
\hline Estudou até o Ensino Fundamental & 1 & & & & & \\
\hline \multicolumn{7}{|l|}{ Situação empregatícia } \\
\hline Empregado & 1,16 & $0,9-1,6$ & 0,322 & & & \\
\hline Não empregado & 1 & & & & & \\
\hline \multicolumn{7}{|l|}{ Renda } \\
\hline Mais de 2 salários mínimos & 1,14 & $0,8-1,5$ & 0,382 & & & \\
\hline De 1 a 2 salários mínimos & 1 & & & & & \\
\hline Tempo de tratamento & & & & & & \\
\hline
\end{tabular}




\begin{tabular}{|c|c|c|c|c|c|c|c|}
\hline \multirow{2}{*}{\multicolumn{2}{|c|}{ Variáveis }} & \multicolumn{6}{|c|}{ Adesão } \\
\hline & & $\mathrm{RPb}$ & IC $95 \%$ & $p$-value & RPaj & IC 95\% & $p$-value \\
\hline De 1 a 3 anos & & 1,7 & $1,2-2,3$ & 0,001 & 1,6 & $1,2-2,1$ & 0,001 \\
\hline Mais de 3 anos & & 1 & & & 1 & & \\
\hline \multicolumn{8}{|c|}{$\begin{array}{l}\text { Acompanhamento no serviço de } \\
\text { saúde }\end{array}$} \\
\hline Apresenta facilidades & & 2,2 & $1,5-3,0$ & 0,000 & 2,0 & $1,5-2,8$ & 0,000 \\
\hline Apresenta dificuldades & & 1 & & & 1 & & \\
\hline \multicolumn{8}{|c|}{ Apresentou doenças oportunistas } \\
\hline Sim & & 1,5 & $1,2-1,9$ & 0,002 & 1,6 & $1,3-2,0$ & 0,000 \\
\hline Não & & 1 & & & 1 & & \\
\hline $\begin{array}{ll}\text { Apresenta } & \text { alguma } \\
\text { psiquiátrica } & \end{array}$ & condição & & & & & & \\
\hline Não & & 2,4 & $1,3-4,6$ & 0,007 & 2,4 & $1,3-4,4$ & 0,005 \\
\hline $\operatorname{Sim}$ & & 1 & & & 1 & & \\
\hline
\end{tabular}

RPb - Razão Prevalência Bruta

RPaj - Razão Prevalência Ajustada

Os adultos com 40 anos ou mais apresentaram uma probabilidade de adesão duas vezes maior do que adultos de 21 a 39 anos. Em relação ao tempo de tratamento, as pessoas com um a três anos de tratamento apresentaram 1,6 vezes mais probabilidade de manter a adesão do que pessoas com mais de três anos de tratamento. As pessoas que manifestaram facilidade em realizar o acompanhamento no serviço de saúde apresentaram duas vezes mais probabilidade de adesão dos que consideravam esse processo difícil (Tabela 3).

As pessoas que expuseram alguma doença oportunista apresentaram uma probabilidade de 1,6 vezes mais de adesão do que aquelas que nunca tiveram nenhuma doença oportunista. Por fim, as pessoas que não tinham nenhuma condição psiquiátrica apresentaram uma probabilidade de 2,4 vezes mais de aderir à terapia antirretroviral do que as pessoas que tinham alguma condição psiquiátrica (Tabela 3).

\section{DISCUSSÃO}

Os achados deste estudo mostram que dentre os fatores sociodemográficos, econômicos, clínicos e comportamentais foi possível identificar que a idade, o tempo de tratamento, o acompanhamento no serviço de saúde, apresentar alguma doença oportunista e não ter nenhuma condição psiquiátrica influenciaram na adesão à terapia antirretroviral. Neste sentido, percebe-se que são múltiplos os fatores que inspiram a adesão à terapia antirretroviral para o HIV, caracterizando, desta forma, a adesão como um processo complexo ${ }^{14}$.

Dentre os fatores demográficos, a idade é considerada um preditor importante na terapia antirretroviral e tem demonstrado uma relação significativa com a adesão. Observa-se que quanto maior é a idade das pessoas, maior é a probabilidade de seguirem o tratamento recomendado ${ }^{5,15}$. Ainda, ao relacionar a idade com a supressão virológica, tem-se que pessoas com idade maior que 45 anos é quase seis vezes mais provável em comparação com aqueles com idade menor de 30 anos $^{19}$. 


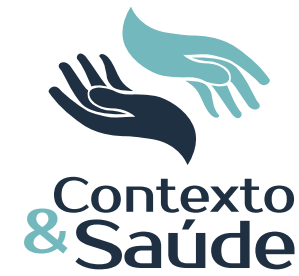

Editora Unijuí - Revista Contexto \& Saúde - ISSN 2176-7114 - v. 21, n. 44, out./dez. 2021 dos níveis de adesão $0^{5,13}$. processo de adoecimento ${ }^{23}$. zação do tratamento antirretroviral ${ }^{24-26}$.
O tempo de tratamento tem sido apontado como fator de influência na adesão, apesar de apresentar escassa literatura e os achados não serem consensuais ou não terem encontrado relação significativa entre as variáveis ${ }^{13,20}$. Tem-se, no entanto, observado que as pessoas que apresentam um menor tempo de tratamento têm maiores chances de manter níveis elevados de adesão em relação a pessoas com longos períodos. Essa condição de temporalidade do tratamento e a adesão pode ser explicada pelo fato de que as pessoas começam a se empenhar em manter a adesão a partir da percepção de eficácia do tratamento na sua condição clínica ${ }^{21}$. Em contrapartida, a melhora da condição de saúde com o passar do tempo pode influenciar na diminuição dos níveis de adesão. A melhora clínica pode remeter à percepção de uma condição saudável, diminuindo a preocupação com o tratamento, e, consequentemente, o não seguimento correto do tratamento prescrito ${ }^{22}$.

As pessoas em terapia antirretroviral para o HIV que apresentam facilidades em seguir o acompanhamento no serviço de saúde têm maiores chances de manter níveis elevados de adesão. O seguimento da terapia antirretroviral vai além da ingestão do medicamento, pois exige frequentemente acompanhamento pelo serviço de saúde, seja para a realização de consultas periódicas seja para a retirada de medicamentos, que devem ocorrer de forma mensal. Existem, no entanto, inúmeras situações que podem dificultar ou fragilizar este acompanhamento, as quais envolvem aspectos sociais, pessoais, expectativa de autoeficácia, apoio social, utilização de transporte municipal ou intermunicipais e trabaIho, dentre outras. Assim, quando conseguem modificar e/ou adaptar sua rotina e seu estilo de vida acabam estando mais motivadas a seguirem o tratamento e realizarem, de forma adequada, o acompanhamento, influenciando na melhora

Ter apresentado alguma doença oportunista mostrou-se como um fator de influência na adesão à terapia antirretroviral. Assim, entende-se que, ao apresentarem alguma infecção oportunista e vivenciar suas complicações, pode ser um motivador para fazê-la aderir à terapia antirretroviral. Na literatura científica, no entanto, foi identificado que pessoas que não tiveram doenças oportunistas eram sete vezes mais propensas a serem aderentes à terapia antirretroviral, do que as pessoas que já apresentaram alguma doença oportunista, o que explica que as pessoas que sofreram por conta de uma doença oportunista e pela imunidade baixa acabam mantendo a adesão à terapia a fim de não passar mais pelo

O fato de não ter nenhuma condição psiquiátrica aumenta a probabilidade de as pessoas aderirem à terapia antirretroviral para o HIV. A presença de alguma condição psicossocial pode desencadear respostas emocionais disfuncionais e padrões negativos de pensamento ${ }^{24}$. Desta forma, a manifestação dos aspectos psicossociais, principalmente a ansiedade e a depressão, que são prevalentes em pessoas com a infecção pelo HIV, comprometem a condição psicológica, que, na maioria das vezes, diminui a percepção de controle, de autoeficácia, de otimismo, reduzindo a habilidade de socialização e de enfrentamento do estresse, repercutindo em atitudes desfavoráveis sobre a percepção da doença e da reali- 
A limitação deste estudo está relacionada à avaliação na adesão à terapia antirretroviral, que foi baseada unicamente por um instrumento que avalia ,de forma recordatória, as condições relacionadas ao tratamento antirretroviral, seja de ingestão ou relacionado ao serviço de saúde, uma vez que não foi possível o acesso aos registros de marcadores biológicos (carga viral e $\mathrm{CD}^{+}$), a fim de relacionar com os dados de adesão o que, de certa forma, garantiria maior clareza nos achados. Por fim, o estudo avaliou a população, que se encontrava na faixa etária de adultos com idade inferior a 60 anos, e não podem os dados serem generalizados para a população de idosos.

\section{CONCLUSÃO}

Este estudo apresentou que, dentre os aspectos demográficos, a idade está associada à adesão. Desta forma, cabe aos profissionais de saúde uma atenção em adultos jovens, melhorando a sua motivação e percepção sobre a doença e o tratamento. Já dentre as variáveis comportamentais, a facilidade em realizar o acompanhamento no serviço de saúde apresentou relação com a adesão. Destaca-se, assim, que, mesmo sendo múltiplos os aspectos que envolvem esta questão, várias condições podem facilitar este processo, como a garantia de transporte, horários alternativos para pessoas que trabalham, assistência multiprofissional, o acompanhamento, apoio e empenho dos profissionais, buscando o estímulo e a motivação em manter a adesão.

Em relação aos aspectos clínicos, ter apresentado uma doença oportunista foi um indicador de adesão, sendo imprescindível que os profissionais da saúde venham informar e dialogar sobre as condições de não aderir de forma correta ao tratamento antirretroviral. A baixa adesão pode levar ao adoecimento, à resistência ao medicamento e até mesmo ao óbito.

O fato de não ter nenhuma condição psiquiátrica é um indicador de meIhora da adesão. Sabendo da forte relação entre os aspectos psicossociais e a não adesão, torna-se essencial a avaliação constante de sintomas ligados à condição psicológica, a fim de possibilitar um acompanhamento e tratamento adequado para auxiliar na motivação para seguir o tratamento.

\section{REFERÊNCIAS}

${ }^{1}$ Unaids. Programa Conjunto das Nações Unidas sobre HIV/Aids. 2020. Estatística. [Acesso em: 16 fev. 2020]. Disponível em: https://unaids.org.br/estatisticas/

${ }^{2}$ Brasil. Ministério da Saúde. 2020. Boletim epidemiológico do HIV. [Acesso em: 16 fev. 2020]. Disponível em: http://www.aids.gov.br/pt-br/taxonomy/term/595

${ }^{3}$ Iacob SA, lacob DG, Jugulete G. Improving the adherence to antiretroviral therapy, a difficult but essential task for a successful HIV treatment - clinical points of view and practical considerations. Frontiers in pharmacology. 2017; 8:1-12. doi: https://doi. org/10.3389/fphar.2017.00831

${ }^{4}$ Altice F, Evuarherhe O, Shina S, Carter G, Beaubrun AC. Adherence to HIV treatment regimens: systematic literature review and meta-analysis. Patient Preference and Adherence. 2019; 13:475-490. doi: https://doi.org/10.2147/PPA.S192735 
${ }^{5}$ Foresto JS, Melo ES, Costa CRB, Antonini M, Gir E, Reis RK. Adesão à terapia antirretroviral de pessoas vivendo com HIV/aids em um município do interior paulista. Rev. Gaúcha Enferm. 2017;38(1):1-7. doi: https://doi.org/10.1590/1983-1447.2017.01.63158

${ }^{6}$ Spinelli MA, Haberer JE, Chai PR, Castilho-Mancilla J, Anderson PL, Gandhi M. Approaches to objectively measure antiretroviral medication adherence and drive adherence interventions. Current HIV/AIDS. 2020;17(4):301-314. doi: https://doi.org/10.1007/ s11904-020-00502-5

${ }^{7}$ Zuge SS, De Paula CC, Padoin SMM. Efetividade de intervenções para a adesão à terapia antirretroviral em adultos com HIV: revisão sistemática. Rev. Esc. Enferm. USP. 2020;54:1-9. doi: https://doi.org/10.1590/S1980-220X2019009803627

${ }^{8}$ Podzamczer D, Rozas N, Domingo P, Ocampo A, Eynde EV, Deig E et al. ACTG-HIV symptoms changes in patients switched to RPV/FTC/TDF due to previous intolerance to CART. Interim analysis of the PRO-STR study. J. Int. AIDS Soc. 2014;17(4):1-2. doi: https://doi.org/10.7448/IAS.17.4.19814

${ }^{9}$ Bezabhe WM, Chalmers L, Bereznicki LR, Peterson GM. Adherence to antiretroviral therapy and virologic failure: a meta-analysis. Medicine (Baltimore). 2016;95(15):1-9. doi: https://doi.org/10.1097/MD.0000000000003361

${ }^{10}$ Costa JM, Torres TS, Coelho LE, LUZ PM. Adherence to antiretroviral therapy for HIV/ AIDS in Latin America and the Caribbean: Systematic review and meta-analisis. Journal of the International AIDS Society. 2018;21:1-20. doi: https://doi.org/10.1002/ jia2.25066

${ }^{11}$ Garbin CCS, Gatto RCJ, Gabin AJI. Adesão à terapia antirretroviral em pacientes HIV soropositivos no Brasil: uma revisão da literatura. Archives of Health investigation. 2017;6(2):65-70. doi: https://doi.org/10.21270/archi.v6i2.1787

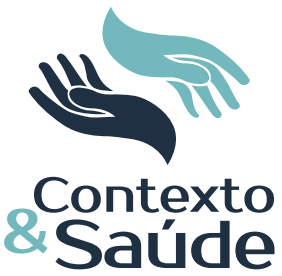

12 WHO. World Health Organization. How AIDS changed everything: MDG 6: 15 years, 15 lessons of hope to the AIDS response. Geneva: WHO; 2015.

13 Zuge SS, Primeira MR, Remor E, Magnago TSBS, Paula CC, Padoin SMM. Fatores associados à adesão ao tratamento antirretroviral em adultos infectados pelo HIV: estudo transversal. Rev. Enferm. UFSM. 2017;7(4):577-589. doi: https://doi. org/10.5902/2179769225657

${ }^{14}$ Goulart S, Meirelles BHS, Costa VT, Pfleger G, Silva LM. Adesão à terapia antirretroviral em adultos com HIV/AIDS atendidos em um serviço de referência. Rev. Min. Enferm, 2018;22:1-6. doi: http://www.dx.doi.org/10.5935/1415-2762.20180050

15 Seidl EMF, Remor E. Adesão ao tratamento, resiliência e percepção de doença em pessoas com HIV. Psicologia: teoria e pesquisa. 2020;26:1-11. doi: https://doi.org/10.1590/0102.3772e36nspe6

${ }^{16}$ Remor E. Valoración de la adhesión al tratamiento antirretroviral en pacientes $\mathrm{VIH}+$ Psicothema. 2002;14(2):262-267.

17 Remor E, Milner-Moskovics J, Preussler G. Adaptação brasileira do "Cuestionario pala la Evaluación de la Adhesión al Tratamiento Antiretroviral. Rev. Saúde Pública. 2007;41(5):685-94. doi: https://doi.org/10.1590/S0034-89102006005000043

${ }^{18}$ Silva BB, Brito A, Monteiro EP. Evidence of validity for the online version of the Assessment of Adherence to Antiretroviral Therapy Questionnaire. SAGE Open. 2019;9(3):112. doi: https://doi.org/10.1177/2158244019877201

${ }^{19}$ Melku M, Abebe G, Teketel A, Asrie F,Yalew A, Diadgo B, et al. Immunological status and virological suppression among HIV-infected adults on highly active antiretroviral therapy. Environmental Health and Preventive Medicine. 2020;25(43):1-9. doi: https://doi. org/10.1186/s12199-020-00881-6

${ }^{20}$ Souza HC, Mota MR, Alves AR, Lima FD, Chaves SN, Dantas ERA, et al. Análise da adesão ao tratamento com antirretrovirais em pacientes com HIV/AIDS. Rev. Bras. Enferm. 2019;72(5):1361-1369. doi: https://doi.org/10.1590/0034-7167-2018-0115

${ }^{21}$ Silva RAR, Nelson ARC, Duarte FHS, Prado NCC, Holanda JRR, Costa DARS. Avaliação da adesão à terapia antirretroviral em pacientes com AIDS. Revista de Pesquisa - cuidado é fundamental. 2017;9(1):15-20. doi: https://doi.org/10.9789/2175-5361.2017. v9i1.15-20 
${ }^{22}$ Blatt CR, Citadin CB, Souza FG, Mello RS, Galato D. Assessment of adherence to antiretroviral drugs in a municipality in southern Brazil. Revista da Sociedade de Medicina Tropical. 2009;42(2):131-136. doi: https://doi.org/10.1590/s0037-86822009000200007

${ }^{23}$ Negash E, Wakgari N, Taye BW, Edris M. Adherence to antiretroviral therapy and its associated factors among HIV positive patients in Nekemte public health institutions, West Ethiopia. HIV \& AIDS Review. 2016;147:1-6. doi: https://doi.org/10.1016/j.hivar.2016.04.004

${ }^{24}$ Pereira KNA, Mello BRL, Barros SF, Seidl EMF. Intervenção cognitivo-comportamental e farmacológica: atuação interdisciplinar na adesão ao tratamento e sintomas psiquiátricos em pessoas soropositivas. Ponta Grossa, PR: Atena Editora, 2019.

25 Silva RFN, Santos DEL, Lima MEF, Santana SM. Terapia cognitivo-comportamental no tratamento de pessoas vivendo com HIV/aids. Brazilian Journal of Development. 2020;6(11):88271-84. doi: https://doi.org/10.34117/bjdv6n11-301

26 Carvalho PMM, Neto RMS, Neto M LR. Fatores de saúde mental associados a não adesão à terapia anti-retroviral: uma revisão sistemática. Revista Saúde Coletiva. 2020;10(57):3665-77. doi: https://doi.org/10.36489/saudecoletiva. 2020v10i57p3665-3690

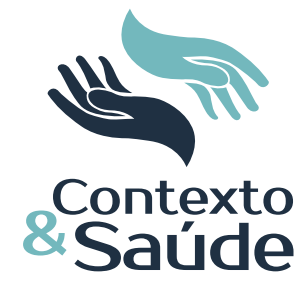

